\title{
Iron carbide nanoplatelets: colloidal synthesis and characterization $\uparrow$
}

Cite this: Nanoscale Adv., 2019, 1, 4476

\author{
Frank M. Abel, (D) *a Shirin Pourmiri, ${ }^{a}$ Georgia Basina, ${ }^{\mathrm{b}}$ Vasileios Tzitzios, (D) *bc \\ Eamonn Devlin ${ }^{c}$ and George C. Hadjipanayis ${ }^{a}$
}

Iron carbide nanoplatelets with an orthorhombic $\mathrm{Fe}_{3} \mathrm{C}$ structure were synthesized following a simple liquid chemical approach. The formation of the carbide phases was shown to depend on the presence of a long chain diol and the reaction temperature. Confirmation of the iron carbide phases and structural characterization was made by X-ray diffraction (XRD) and Mössbauer spectroscopy. Particle morphology was characterized by transmission electron microscopy (TEM) and HR-TEM and the magnetic properties were measured with magnetometry (VSM). The sample with the $\mathrm{Fe}_{3} \mathrm{C}$ phase shows a ferromagnetic behavior with a magnetization of $139 \mathrm{emu} \mathrm{g}^{-1}$ under a $30 \mathrm{kOe}$ applied field. The simple methodology presented here for producing iron carbide nanoplatelets has promising application in the biomedical and catalyst industries.

Received 22nd August 2019
Accepted 6th October 2019

DOI: $10.1039 / c 9 n a 00526 a$

rsc.li/nanoscale-advances

phases, such as high pressure and temperature methods, ${ }^{6-8}$ laser $^{9-12}$ and physical ${ }^{13-16}$ pyrolysis, sol-gel synthesis, ${ }^{17-20}$ gassolid methods, ${ }^{21-23}$ sonolysis followed by thermal treatment, ${ }^{24}$ flame spray synthesis, ${ }^{25}$ laser ablation, ${ }^{26}$ and thermal treatment of amorphous oxides. ${ }^{27}$ However, these methods typically lead to mixtures of various iron carbide phases and poor nanostructural uniformity. ${ }^{3,4}$ More recently, liquid phase chemical methods have been found to produce uniform iron carbide nanoparticles; however, the methods usually use multistep processes and harsh precursors such as $\mathrm{Fe}(\mathrm{CO})_{5}{ }^{3,4}$ Additionally, Ge et al. showed that iron carbide nanoparticles could be synthesized by using amorphous Fe nanoparticles produced by sodium borohydride reduction of iron(II) chloride, which were then heated in oleylamine to $330{ }^{\circ} \mathrm{C}$ for different times producing the $\mathrm{Fe}_{5} \mathrm{C}_{2}$ structure. ${ }^{28}$

In this study, we report a colloidal synthesis of iron carbide nano-platelets. Chemical synthesis leads to single iron carbide phase materials with $79 \% \mathrm{Fe}_{3} \mathrm{C}$ with a magnetization of 139 emu $\mathrm{g}^{-1}$ under a $30 \mathrm{kOe}$ applied field. Identification of the $\mathrm{Fe}_{3} \mathrm{C}$ phase and phase percentage is carried out by Mössbauer spectroscopy. From our knowledge, this is the first single-step liquid chemical synthesis of $\mathrm{Fe}_{3} \mathrm{C}$ nanoplatelets produced without the use of an $\mathrm{Fe}(\mathrm{CO})_{5}$ iron precursor.

\footnotetext{
aDepartment of Physics and Astronomy, University of Delaware, Newark, DE 19716, USA.E-mail:fabel@udel.edu; frank.m.abeliii@gmail.com

${ }^{b}$ Department of Chemical Engineering, Khalifa University of Science and Technology, Petroleum Institute, P. O. Box 2533, Abu Dhabi, United Arab Emirates

'Institute of Nanoscience and Nanotechnology, NCSR Demokritos, Athens, 15310, Greece. E-mail: v.tzitzios@inn.demokritos.gr

$\dagger$ Electronic supplementary information (ESI) available: Mössbauer spectroscopy of the sample synthesized at $300{ }^{\circ} \mathrm{C}$ for 1 hour followed by $340{ }^{\circ} \mathrm{C}$ for 2 hours. See DOI: $10.1039 /$ c9na00526a
}

\section{Experimental methods}

Synthesis of iron carbide

The samples were synthesized by combining $\mathrm{Fe}(\mathrm{acac})_{3}, 1,2-$ hexadecanediol, and palmitic acid as the surfactant in oleylamine as the primary solvent at room temperature. The precursors were magnetically stirred for 2 hours under continuous purging with $\mathrm{H}_{2} / \mathrm{Ar}$ gas. A typical experiment used 0.5 
mmol Fe(acac) $)_{3}, 2 \mathrm{mmol}$ 1,2-hexadecanediol, and $200 \mathrm{mg}$ palmitic acid in $20 \mathrm{~mL}$ oleylamine. To produce a higher yield for Mössbauer spectroscopy measurements, the precursor quantities were quadrupled in the same solvent volume for the two experiments at the highest reaction temperatures. The solution was then heated to temperatures between $260{ }^{\circ} \mathrm{C}$ and $320^{\circ} \mathrm{C}$ for 1 hour. An additional experiment was performed in which the solution was heated to $300{ }^{\circ} \mathrm{C}$ for 1 hour followed by heating to $340{ }^{\circ} \mathrm{C}$ for 2 hours. After cooling the solution to room temperature, the material was precipitated with ethanol and magnetically separated from the solution. Additional washing was done using ultra-sonication and magnetic separation with both ethanol and hexane to remove excess organic material. The materials were either dried in air/desiccator, forming a black powder, or dispersed in ethanol for characterization.

\section{Materials characterization}

The crystal structure of the materials was determined using Xray diffraction (XRD, Rigaku Ultima IV) with $\mathrm{Cu} \mathrm{K} \alpha$ radiation; additional structural characterization and phase analysis were performed by Mössbauer spectroscopy (constant acceleration spectrometer, Janis cryostat, $\mathrm{Co}^{57}(\mathrm{Rh})$ source, calibrated with thin $\alpha$-Fe foil) on selected samples. The size and morphology of the particles were determined using transmission electron microscopy (TEM, JEOL JEM-3010) and the magnetic properties were measured with a 3 Tesla vibration sample magnetometer (VSM, Quantum Design).

\section{Results and discussion}

The formation mechanism and crystal structure of iron carbide were studied using powder X-ray diffraction (XRD). Fig. 1(a) shows the XRD patterns of samples synthesized at different reaction temperatures. The data show that identifiable iron carbide structures begin to form at $300{ }^{\circ} \mathrm{C}$. The XRD patterns of samples synthesized at $300{ }^{\circ} \mathrm{C}$ and $320{ }^{\circ} \mathrm{C}$ are compared to simulated reference patterns in Fig. 1(b), and show the main phase to be orthorhombic $\mathrm{Fe}_{3} \mathrm{C}$. The step reaction performed at $300{ }^{\circ} \mathrm{C}$ for 1 hour followed by $340{ }^{\circ} \mathrm{C}$ for 2 hours leads to a mixture of $\mathrm{Fe}-\mathrm{C}$ phases. At $260{ }^{\circ} \mathrm{C}$, two broad peaks are
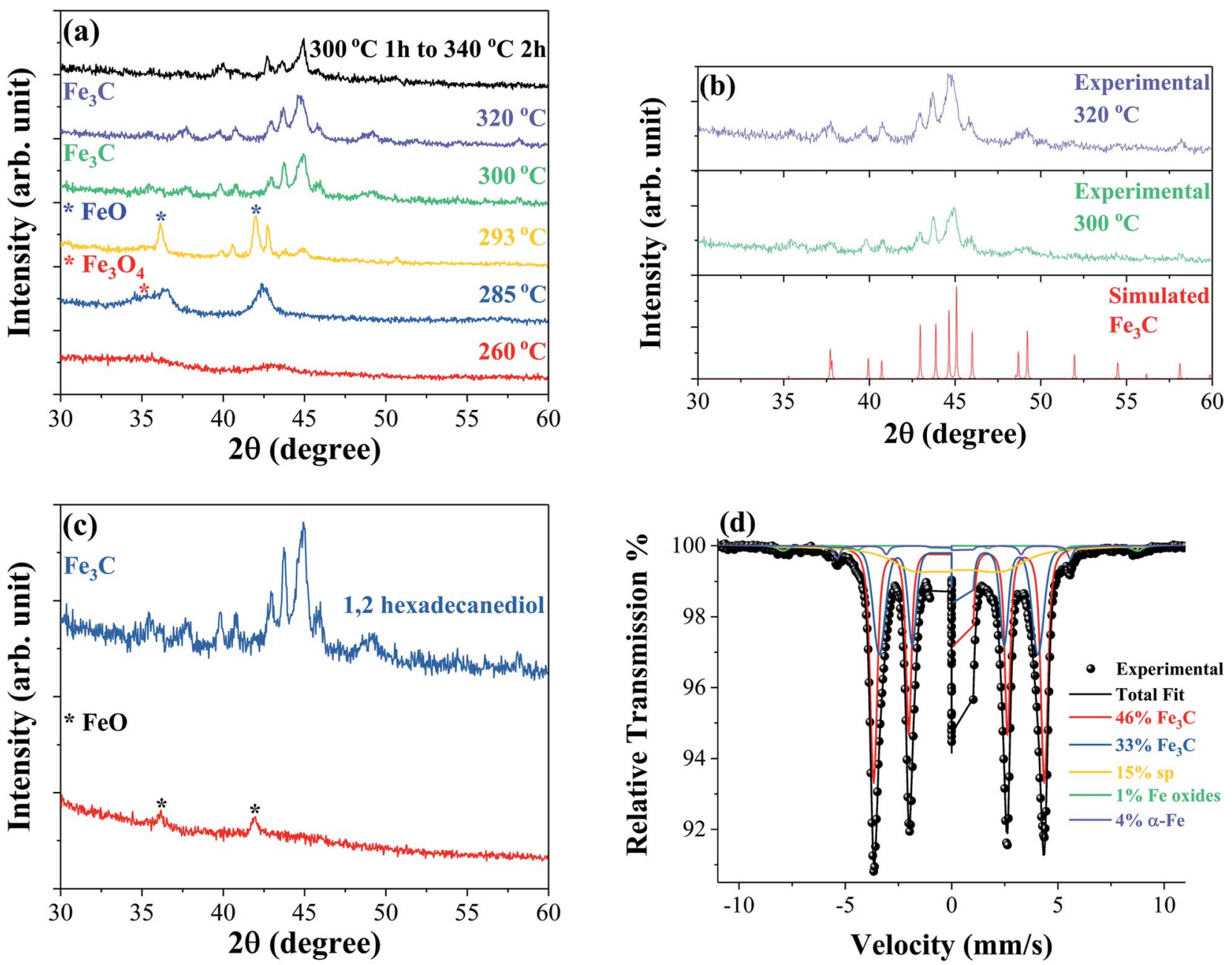

(d)

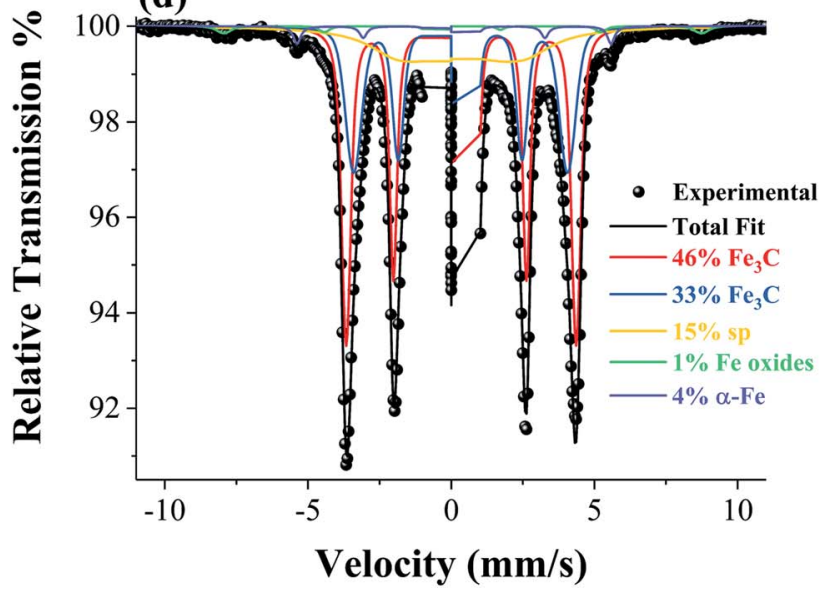

Fig. 1 XRD patterns measured at room temperature of samples synthesized at different reaction temperatures (a), samples synthesized at $300{ }^{\circ} \mathrm{C}$ and $320{ }^{\circ} \mathrm{C}$ in comparison to the simulated $\mathrm{Fe}_{3} \mathrm{C}$ structure obtained using PowderCell. ${ }^{29}$ Structural data for orthorhombic Fe ${ }_{3} \mathrm{C}$ simulations acquired from ICSD-99002 (b) and samples synthesized at $300{ }^{\circ} \mathrm{C}$ for 1 hour with and without 2 mmol 1,2-hexadecanediol (c). Mössbauer spectroscopy performed at $80 \mathrm{~K}$ of a sample synthesized at $320^{\circ} \mathrm{C}$ confirming the formation of the Fe ${ }_{3} \mathrm{C}$ structure (d). 
observed indicating an amorphous or nanocrystalline material. The main peak observed at $42.98^{\circ}$ has a corresponding $d$ spacing of $0.210 \mathrm{~nm}$; the peaks and relative intensities have similarities to $\mathrm{FeO}$ peaks, but are shifted to higher angles possibly indicating that under these conditions, an iron rich $\mathrm{FeO}$ structure forms. Increasing the temperature to $285{ }^{\circ} \mathrm{C}$ causes the main peak of the structure to shift to a lower angle of $42.42^{\circ}$, corresponding to a $d$-spacing of $0.213 \mathrm{~nm}$, possibly indicating a similar iron rich $\mathrm{FeO}$ structure. The shoulder to the left of the peak at $\sim 36^{\circ}$ is believed to belong to either $\mathrm{Fe}_{3} \mathrm{O}_{4}$ or $\mathrm{Fe}_{2} \mathrm{O}_{3}$. At $293^{\circ}$ the main phase is clearly identified as $\mathrm{FeO}$ with a main peak at $41.99^{\circ}$, corresponding to a $d$-spacing of 0.215 $\mathrm{nm}$, coinciding with the (200) diffraction plane. In addition to the $\mathrm{FeO}$ phase, there are one or more unidentifiable phases which may be intermediate $\mathrm{Fe}-\mathrm{C}$ structures. Fig. 1(c) compares a reaction performed at $300{ }^{\circ} \mathrm{C}$ as described in the experimental section but without the addition of the 1,2-hexadecanediol reducing agent. The XRD patterns show that in the absence of 1,2-hexadecanediol only the $\mathrm{FeO}$ phase, identified by the peaks at $\sim 42^{\circ}$ and $\sim 36^{\circ}$, forms. With the addition of 1,2-hexadecanediol, the iron carbide phase $\mathrm{Fe}_{3} \mathrm{C}$ forms. The results suggest clearly that the carbon source for metal carbide formation is the 1,2-hexadecanediol molecule. The carbon becomes available via the oxidation cleavage of the diol into esters, ketones or aldehydes in the presence of $\mathrm{Fe}^{3+}$ ions acting as the oxidant, which are then reduced to the $\mathrm{Fe}^{2+}$ state.

Mössbauer spectroscopy was performed on selected samples to identify the iron carbide phases formed during the synthesis. Fig. 1(d) shows the Mössbauer spectrum of the sample synthesized at $320{ }^{\circ} \mathrm{C}$ obtained at $80 \mathrm{~K}$; the fitting analysis confirms $\mathrm{Fe}_{3} \mathrm{C}$ as the majority phase, making up $79 \%$ of the sample. Two

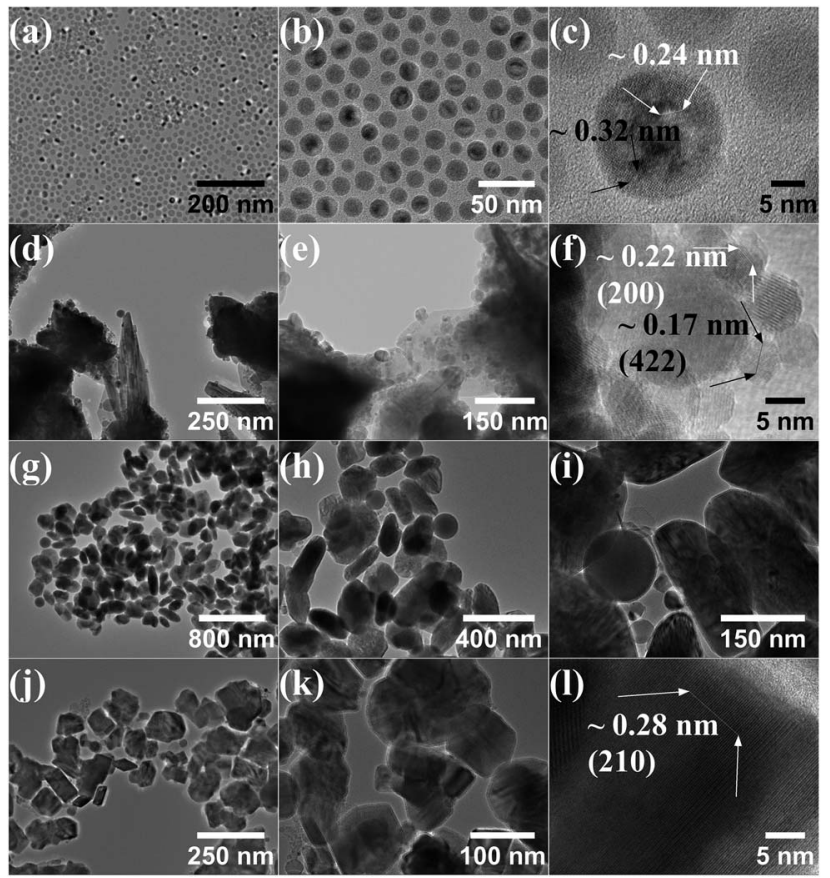

Fig. 2 TEM of samples synthesized at $285^{\circ} \mathrm{C}(a-c), 300^{\circ} \mathrm{C}(\mathrm{d}-\mathrm{f}), 320$ ${ }^{\circ} \mathrm{C}(\mathrm{g}-\mathrm{i})$, and $300{ }^{\circ} \mathrm{C}$ for 1 hour followed by $340{ }^{\circ} \mathrm{C}$ for 2 hours $(\mathrm{j}-\mathrm{l})$. subspectra are used to approximate the $\mathrm{Fe}_{3} \mathrm{C}(46 \%$ and $33 \%)$ phase indicating some slight compositional variation in the phase. In addition to $\mathrm{Fe}_{3} \mathrm{C}$, the spectra reveal small percentages of ferromagnetic iron oxides, $\alpha$ - $\mathrm{Fe}$, and a relaxing/superparamagnetic (sp) component. Mössbauer spectroscopy was also performed on the sample produced by the step reaction with a synthesis temperature of $300{ }^{\circ} \mathrm{C}$ for 1 hour followed by $340{ }^{\circ} \mathrm{C}$ for 2 hours. The spectrum obtained at $4.2 \mathrm{~K}$ reveals a mixture of $\mathrm{Fe}_{5} \mathrm{C}_{2}, \mathrm{Fe}_{3} \mathrm{C}$, and iron oxide phases in this sample, as shown in the ESI Fig. S1. $\dagger$

The size and morphology of the particles obtained by TEM for the samples synthesized at $285^{\circ} \mathrm{C}, 300^{\circ} \mathrm{C}, 320^{\circ} \mathrm{C}$, and step reaction with maximum temperature of $340{ }^{\circ} \mathrm{C}$ are shown in Fig. $2(\mathrm{a}-\mathrm{l})$. At $285{ }^{\circ} \mathrm{C}$ the particles show a uniform spherical morphology, Fig. 2(a and b). HR-TEM in Fig. 2(c) suggests a possible core-shell or polycrystalline structure with a different $d$-spacing for the surface versus the interior of the particle. When the reaction temperature is increased to $300{ }^{\circ} \mathrm{C}$, corresponding to the emergence of the $\mathrm{Fe}_{3} \mathrm{C}$ phase, the morphology changes significantly showing variable sized spherical particles together with larger platelet structures, Fig. 2(d and e). The smaller spherical particles appear on the surface or within the platelet structures. HR-TEM in Fig. 2(f) shows the $d$-spacing measurements of two of the spherical particles with a $d$-spacing of $0.17 \mathrm{~nm}$, close to that of the $\mathrm{Fe}_{3} \mathrm{O}_{4}$ diffraction plane (422), and a $d$-spacing of $0.22 \mathrm{~nm}$, close to that of the FeO diffraction plane (200). At $320{ }^{\circ} \mathrm{C}$ the material shows a more uniform platelet morphology with an average size of $210 \mathrm{~nm}$ found by averaging the approximate length and width of a selection of particles from TEM micrographs. Small spherical nanoparticles are no longer clearly observed on the surface/interior of the platelets, Fig. 2(h and i). In the step reaction, more facetted platelets are observed compared to the material synthesized at $320{ }^{\circ} \mathrm{C}$ with HR-TEM $d$-spacing measurements giving a value of $0.28 \mathrm{~nm}$, close to that of the $\mathrm{Fe}_{5} \mathrm{C}_{2}$ (211) diffraction plane.

Room temperature hysteresis loops are shown in Fig. 3(a) for the samples synthesized at $285{ }^{\circ} \mathrm{C}, 293{ }^{\circ} \mathrm{C}, 320{ }^{\circ} \mathrm{C}$, and after a step reaction with a maximum temperature of $340^{\circ} \mathrm{C}$. At 285 ${ }^{\circ} \mathrm{C}$ the nanoparticles are most likely superparamagnetic at room temperature with zero coercivity; increasing the synthesis temperature to $293{ }^{\circ} \mathrm{C}$ results in observable ferromagnetic behaviour with a coercivity of 141 Oe and a magnetization of 51 emu g ${ }^{-1}$ under a $30 \mathrm{kOe}$ applied field. When the $\mathrm{Fe}_{3} \mathrm{C}$ phase is formed, the magnetization increases to $139 \mathrm{emu} \mathrm{g}^{-1}$ (at $30 \mathrm{kOe}$ ) with a coercivity of $165 \mathrm{Oe}$. In the step reaction sample, which leads to a mixture of $\mathrm{Fe}_{3} \mathrm{C}$ and $\mathrm{Fe}_{5} \mathrm{C}_{2}$ phases, the magnetization at $30 \mathrm{kOe}$ decreases to $114 \mathrm{emu} \mathrm{g}^{-1}$ with a coercivity of $226 \mathrm{Oe}$. The decrease in magnetization relative to the sample with the majority $\mathrm{Fe}_{3} \mathrm{C}$ nanoplatelets is most likely due to the increased carbon content in the $\mathrm{Fe}_{5} \mathrm{C}_{2}$ phase, in addition to slight differences in iron oxide phases and $\alpha$-Fe. Thermomagnetic measurements were performed on the sample with the majority $\mathrm{Fe}_{3} \mathrm{C}$ phase synthesized at $320^{\circ} \mathrm{C}$, as shown in Fig. 3(b). Taking the square of the magnetization and extrapolating it linearly near the transition temperature to the intersection of a horizontal line from the minimum magnetization values, the Curie temperature was found to be approximately $535 \mathrm{~K}$. A previous 

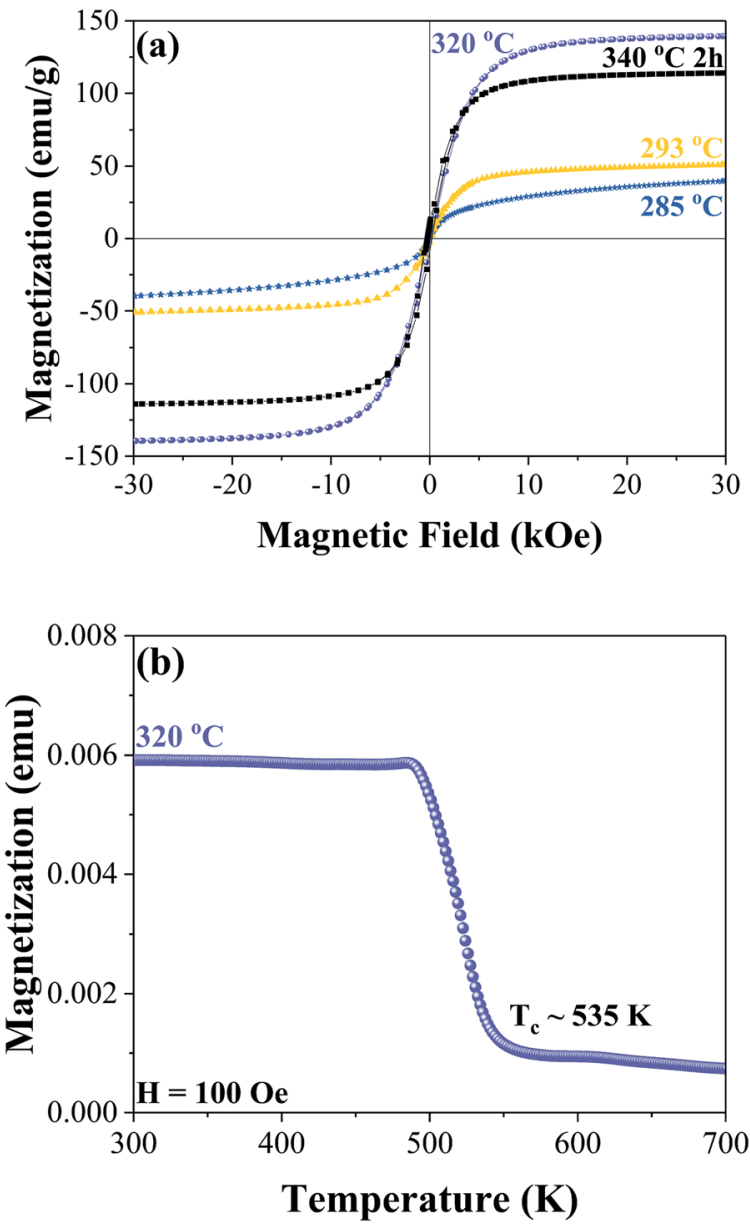

Fig. 3 Room temperature hysteresis curves of samples synthesized at $285^{\circ} \mathrm{C}$ (blue), $293^{\circ} \mathrm{C}$ (yellow), $320^{\circ} \mathrm{C}$ (purple), and $300^{\circ} \mathrm{C}$ for 1 hour followed by $340{ }^{\circ} \mathrm{C}$ for 2 hours (black) (a). Thermomagnetic measurements of the sample synthesized at $320{ }^{\circ} \mathrm{C}$ showing an approximate Curie temperature of $535 \mathrm{~K}(\mathrm{~b})$.

report on bulk iron carbide found a value of $483 \mathrm{~K}$ for the $\mathrm{Fe}_{3} \mathrm{C}$ phase. ${ }^{6}$ The value of $535 \mathrm{~K}$ is closer to what has been reported for $\mathrm{Fe}_{7} \mathrm{C}_{3}$ with a Curie temperature of $523 \mathrm{~K}$ (ref. 6) or $\mathrm{Fe}_{5} \mathrm{C}_{2}$ with a Curie temperature of $538 \mathrm{~K}^{30}$ Tsuzuki et al. presented SEM images showing an irregular grain structure that is micrometres in size. ${ }^{6}$ In the case of $\mathrm{Fe}_{5} \mathrm{C}_{2}$ the Curie temperature value is given without indication of the microstructure. ${ }^{30}$ Since the assynthesized sample is approximately $210 \mathrm{~nm}$ in size, it is unlikely that the difference in Curie temperature is attributed to a size effect when compared to the bulk. The difference in Curie temperatures may be related to our chemically synthesized $\mathrm{Fe}_{3} \mathrm{C}$ phase being more Fe rich relative to the reported bulk value by Tsuzuki et al. This is consistent with the lower saturation magnetization of $125 \mathrm{emu}^{-1}$ for their sample. ${ }^{6}$

\section{Conclusions}

In conclusion, we developed a simple colloidal method for the synthesis of iron carbide nanoplatelets. The 1,2-hexadecanediol seems to play multiple roles in the reaction. First, it works as a reducing agent for $\mathrm{Fe}^{3+}$ reduction to the zero valence state, followed by a carbonization step at reaction temperatures higher than $300{ }^{\circ} \mathrm{C}$. The sample synthesized at $320{ }^{\circ} \mathrm{C}$ exhibits a strong ferromagnetic behavior which is due to the presence of the iron carbide phase orthorhombic $\mathrm{Fe}_{3} \mathrm{C}$. The sample had a high magnetization of $139 \mathrm{emu}^{-1}$ under a $30 \mathrm{kOe}$ applied field. The simple solution synthesis method presented is promising for utilizing iron carbide nanomaterials for biomedical and catalytic applications.

\section{Conflicts of interest}

There are no conflicts to declare.

\section{Acknowledgements}

This work has been supported by the DOE-BES program under the grant DE-FG02-90ER45413 at the University of Delaware. We also acknowledge support for this work from the project MIS 5002567, implemented under the "Action for the Strategic Development on the Research and Technological Sector", funded by the Operational Programme "Competitiveness, Entrepreneurship and Innovation" (NSRF 2014-2020) and cofinanced by Greece and the European Union (European Regional Development Fund).

\section{Notes and references}

1 T. Niu, Nano Today, 2018, 18, 12-14.

2 W. Yang, S. Rehman, X. Chu, Y. Hou and S. Gao, ChemNanoMat, 2015, 1, 445.

3 A. Meffre, B. Mehdaoui, V. Kelsen, P. F. Fazzini, J. Carrey, S. Lachaize, M. Respaud and B. Chaudret, Nano Lett., 2012, 12, 4722-4728.

4 C. Yang, H. Zhao, Y. Hou and D. Ma, J. Am. Chem. Soc., 2012, 134, 15814-15821.

5 K. Xu, B. Sun, J. Lin, W. Wen, Y. Pei, S. Yan, M. Qiao, X. Zhang and B. Zong, Nat. Commun., 2014, 5, 5783.

6 A. Tsuzuki, S. Sago, S.-I. Hirano and S. Naka, J. Mater. Sci., 1984, 19, 2513-2518.

7 H. Song and X. Chen, Chem. Phys. Lett., 2003, 374, 400-404. 8 S. Zoë, S. C. Wimbush, M. Antonietti and C. Giordano, Chem. Mater., 2010, 22, 5340-5344.

9 G. T. Hager, X. X. Bi, F. J. Derbyshire, P. C. Eklund and J. M. Stencel, J. Am. Chem. Soc., 1991, 202, 51.

10 J. M. Stencel, P. C. Eklund, X. X. Bi, G. H. Davis, G. T. Hager and F. J. Derbyshire, Stud. Surf. Sci. Catal., 1993, 75, 1797.

11 A. R. Sethuraman, J. M. Stencel, A. M. Rubel, B. Cavin and C. R. Hubbard, J. Vac. Sci. Technol., A, 1994, 12, 443-451.

12 X. Q. Zhao, Y. Liang, Z. Q. Hu and B. X. Liu, J. Appl. Phys., 1996, 80, 5857-5860.

13 I. K. Herrmann, R. N. Grass, D. Mazunin and W. J. Stark, Chem. Mater., 2009, 21, 3275-3281.

14 E. P. Sajitha, V. Prasad, S. V. Subramanyam, A. K. Mishra, S. Sarkar and C. Bansal, J. Phys.: Condens. Matter, 2007, 19, 046214. 
15 J. H. Kim, J. Kim, J. H. Park, C. K. Kim, C. S. Yoon and Y. Shon, Nanotechnology, 2007, 18, 115609.

16 O. Schneeweiss, R. Zbořil, B. David, M. Heřmánek and M. Mashlan, Isiame 2008, 2009, pp. 167-173.

17 C. Giordano, C. Erpen, W. Yao, B. Milke and M. Antonietti, Chem. Mater., 2009, 21, 5136-5144.

18 S. Zoë, S. C. Wimbush, M. Antonietti and C. Giordano, Chem. Mater., 2010, 22, 5340-5344.

19 C. Giordano, A. Kraupner, S. C. Wimbush and M. Antonietti, Small, 2010, 6, 1859-1862.

20 Z. Schnepp, W. Yang, M. Antonietti and C. Giordano, Angew. Chem., 2010, 122, 6714-6716.

21 L. C. Browning, T. W. Dewitt and P. H. Emmett, J. Am. Chem. Soc., 1950, 72, 4211.

22 H. H. Podgurski, J. T. Kummer, T. W. Dewitt and P. H. Emmett, J. Am. Chem. Soc., 1950, 72, 5382-5388.
23 L. C. Browning and P. H. Emmett, J. Am. Chem. Soc., 1951, 73, 581-583.

24 S. I. Nikitenko, Y. Koltypin, O. Palchik, I. Felner, X. N. Xu and A. Gedanken, Angew. Chem., 2001, 113, 4579-4581.

25 I. K. Herrmann, R. N. Grass, D. Mazunin and W. J. Stark, Chem. Mater., 2009, 21, 3275-3281.

26 V. Amendola, P. Riello and M. Meneghetti, J. Phys. Chem. C, 2010, 115, 5140-5146.

27 O. Schneeweiss, R. Zbořil, B. David, M. Heřmánek and M. Mashlan, Isiame 2008, 2009, pp. 167-173.

28 W. Ge, W. Gao, J. Zhu and Y. Li, J. Alloys Compd., 2019, 781, 1069-1073.

29 W. Kraus and G. Nolze, J. Appl. Crystallogr., 1996, 29, 301303.

30 X.-W. Liu, S. Zhao, Y. Meng, Q. Peng, A. K. Dearden, C.-F. Huo, Y. Yang, Y.-W. Li and X.-D. Wen, Sci. Rep., 2016, 6, 26184 . 